\title{
Tensile strength analysis of aramid fabric of firefighter's clothing after accelerated aging and abrasion
}

\author{
Renata Kamocka-Bronisz ${ }^{1, *}$ \\ ${ }^{1}$ The Main School of Fire Service, Faculty of Fire Safety Engineering, 52/54 Slowackiego St., 01-629 \\ Warsaw, Poland
}

\begin{abstract}
A firefighter's clothing as a personal protection used during rescue actions needs to fulfil several requirements in order to provide the optimum safety level. Author made an attempt to evaluate durability of the selected aramid material used as an outer layer of firefighter's clothing. Verification of material's durability was performed based on the tensile strength studies of the raw sample of material, and material subjected to accelerated aging in the chamber with xenon lamp and by Martindale's abrasion cycles. The tensile tests were carried out in accordance with PNEN ISO 13934-1:2013-07 standard, which specifies procedure to determine the maximum force of textile fabrics using a strip method.The test results show a decrease in the tensile strength of a fabric exposed to UV radiation and after abrasion cycles. In case of material exposure to UV radiation for 100 and 200 hours, reduction of strength by 34 and $48 \%$ was observed, respectively. Analysing the results obtained during the tensile testing of the material, which was subjected to abrasion in cycles of 20,000 and 40,000 , the strength level decreased by 52 and $80 \%$, respectively.
\end{abstract}

\section{Introduction}

A dedicated firefighter's clothing should provide an optimum protection against the threats. In the production more and more advanced materials with increasingly better parameters are used. Protecting clothing has to protect rescuer against such threats as mechanical impacts, thermal and chemical impacts. Protective characteristics of clothing should be maintained during its whole lifetime.

The main objective of the article is tensile strength analysis of the outer layer of special firefighter's clothing after cycles of accelerated wear consisting of xenon lamp effect, including ultraviolet and abrasion wear. The test allowed evaluating stability of the outer layer of clothing after use.

\footnotetext{
*Corresponding author: r.kamocka@sgsp.edu.pl
} 


\section{Requirements for special clothing according to PN-EN 469:2008 standard}

Special clothing in order to be released for use has to undergo several studies confirming its effectiveness. According to PN-EN 469:2008 [1] standard the following studies are conducted: tensile strength studies of the outer material, tearing strength, material stability after exposure to heat and other.

One of the requirements resulting from PN-EN 469:2008 standard is tensile strength of outer material. According to 6.6.1 „,Outer fabric, studied according to EN ISO 13934-1 or EN ISO 1421:1998, method 1, should in both in longitudinal and transverse direction be characterized by strength $\geq 450 N^{\prime \prime}$.

\section{Impact of sun radiation and attrition on the strength of fabrics}

\subsection{Sun radiation}

Protective clothing is subjected to sun radiation including ultraviolet (UV) causing degradation of textile material. A long term exposure to radiation can lead to changes of physicochemical properties. The absorbed radiation can cause photo-lytic and photooxidative reactions in the material. The reactions lead to break of fibre-forming polymer chains, which connections ensure good fibre quality. [2]

For the selected outer layer of fabric of special clothing, ageing studies in the aging chamber with xenon lamp were conducted. It allowed for evaluation how fabric strength parameters changed after long-term exposure to radiation in UV and visible light range. Control of intensity enables obtaining faster ageing effect. According to specifications of the aging chamber manufacturer at $600 \mathrm{~W} / \mathrm{m}^{2}$ radiation intensity in wavelength range 300 $800 \mathrm{~nm}$, during 79 hours the fabric was subjected to radiation, which in normal conditions in the Middle Europe would last 1 month. Earlier studies conducted at the Mechanics Division of the Main School of Fire Services have shown in case of aramid fibres lower resistance to UV radiation effect compared to cotton fabrics. It is related to photo degradation of polymers $[3,4]$.

\subsection{Material abrasion}

During use of special clothing material abrasion occurs most often at the knee height, crotch and elbows. There is a slow damage to the fibres of the outer layer of the material, which loses its properties and strength.

Evaluation of material's abrasion resistance after Martindale's test allows determining at what degree of wear the clothing still maintains its properties.

Author's own studies described in [5] confirmed higher resistance to mechanical abrasion of aramid fibres compared to impregnated cotton fabrics.

\section{Study description}

\subsection{Studied material}

Laboratory tests were conducted on the outer layer of special clothing. The studies were carried out after exposure to two external factors: visible light radiation and UV, as well as material's abrasion. 
A studied material was an aramid fabric containing:

- $75 \%$ Nomex,

- $23 \%$ Kevlar,

- $2 \%$ P140,

- Weight $195 \mathrm{~g} / \mathrm{m}^{2}$.

Nomex and Kevlar show high abrasion strength, while Kevlar has a higher resistance to UV degradation. Nomex contains polymer in its structure, which disintegrates at long exposure to sun radiation, thus becomes less resistant, fragile and stiff.

\subsection{Sample preparation}

Rectangular samples of two dimensions $5 \times 20 \mathrm{~cm}$ and $3.5 \times 20 \mathrm{~cm}$ were prepared. The prepared samples were cut along the fibres. In total 18 strength tests were carried out.

For the research purposes the following sets of samples were prepared: in raw form with dimensions of $5 \times 20 \mathrm{~cm}$, after ageing with xenon lamp for 100 hours and 200 hours, as well as in a raw form with dimensions of $3.5 \times 20 \mathrm{~cm}$, after 20000 abrasion cycles and 40000 abrasion cycles. Materials were exposed to xenon lamp radiation with daylight filter of intensity of $600 \mathrm{~W} / \mathrm{m}^{2}$ in wavelength range of $300-800 \mathrm{~nm}$ in the ageing chamber Suntest XLS+ by Atlas. Radiation dose after $100 \mathrm{~h}$ was $215976 \mathrm{~kJ} / \mathrm{m}^{2}$. The abrasion of fabric was performed by means of Martindale M235 from SDLATLAS. After conditioning of samples, the tensile strength studies were conducted according to PN-EN ISO 13934-1:2013-07 standard [6].

\section{Summary and analysis of study results}

\subsection{Raw fabric}

Below tensile strength results obtained for raw fabric with dimensions of $5 \times 20 \mathrm{~cm}$ and $3.5 \times 20 \mathrm{~cm}$ are presented.

- Fabric sample with dimensions of 5 x $20 \mathrm{~cm}$

Table 1. Study results for the raw fabric samples with dimensions of $5 \times 20 \mathrm{~cm}$.

\begin{tabular}{|c|c|c|c|c|}
\hline & Sample 1 & Sample 2 & Sample 3 & Average value \\
\hline Thickness [mm] & 0,41 & 0,41 & 0,41 & 0,41 \\
\hline Weight [g/cm $\mathbf{2}]$ & 0,02155 & 0,02155 & 0,02155 & 0,02155 \\
\hline Destructive force value FH [N] & 1289,23 & 1319,18 & 1204,92 & 1271,12 \\
\hline
\end{tabular}

- Fabric sample with dimensions of $3.5 \times 20 \mathrm{~cm}$

Table 2. Raw fabric study results with dimensions of $3.5 \times 20 \mathrm{~cm}$.

\begin{tabular}{|c|c|c|c|c|}
\hline & Sample 1 & Sample 2 & Sample 3 & Average value \\
\hline Thickness [mm] & 0,41 & 0,41 & 0,41 & 0,41 \\
\hline Weight $\left[\mathbf{g} / \mathbf{c m}^{\mathbf{2}}\right]$ & 0,02155 & 0,02155 & 0,02155 & 0,02155 \\
\hline Destructive force value FH [N] & 987,33 & 758,82 & 900,53 & 882,23 \\
\hline
\end{tabular}

\subsection{Fabric after cycles of accelerated aging}

Below the results of tensile strength studies of fabric samples after 100 and 200 hours of xenon lamp radiation in UV and visible light range are presented. 
- Sample after 100 hours of radiation

Table 3. Study results after 100 hours of aging with UV radiation, sample's dimensions $5 \times 20 \mathrm{~cm}$.

\begin{tabular}{|c|c|c|c|c|}
\hline & Sample 1 & Sample 2 & Sample 3 & Average value \\
\hline Thickness [mm] & 0,41 & 0,41 & 0,41 & 0,41 \\
\hline Weight [g/cm $\mathbf{2}]$ & 0,0204 & 0,0192 & 0,0202 & 0,0199 \\
\hline $\begin{array}{c}\text { Destructive force value FH } \\
{[\mathbf{N}]}\end{array}$ & 874,90 & 802,84 & 824,31 & 834,02 \\
\hline
\end{tabular}

- Specimen after 200 hours of radiation

Table 4. Study results after 200 hours of aging with UV radiation, sample's dimensions 5 x $20 \mathrm{~cm}$.

\begin{tabular}{|c|c|c|c|c|}
\hline & Sample 1 & Sample 2 & Sample 3 & Average value \\
\hline Thickness [mm] & 0,41 & 0,41 & 0,41 & 0,41 \\
\hline Weight [g/cm $]$ & 0,0206 & 0,0197 & 0,0192 & 0,0198 \\
\hline Destructive force value FH [N] & 663,09 & 653,97 & 675,51 & 664,19 \\
\hline
\end{tabular}

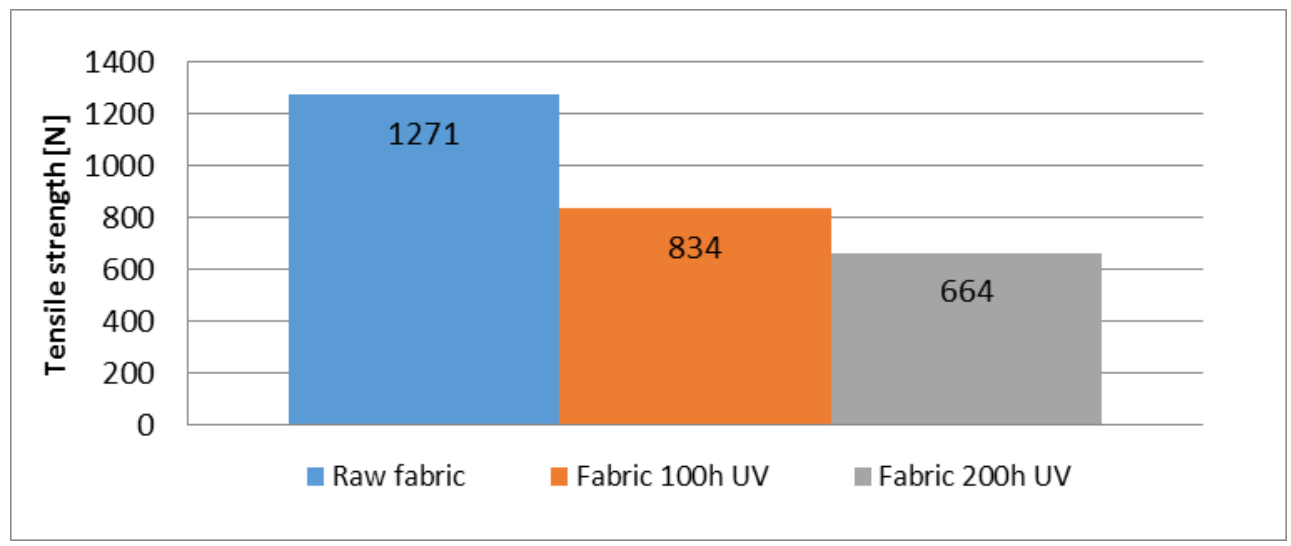

Fig. 1. A figure of average values of tensile strength of a fabric after exposure to radiation References: own studies

The obtained results of ageing studies of samples after $100 \mathrm{~h}$ and 200 hours indicated significant decrease of material's strength. For the samples, which were exposed to accelerated ageing a discolouration of fabric has been observed as well as in touch, the fabric has become stiffer. In case of fabric, which was exposed to UV radiation during 100 $\mathrm{h}$, a difference in strength compared to raw fabric $5 \times 20 \mathrm{~cm}$ was about $34 \%$, while during exposure for $200 \mathrm{~h}$ strength decrease was about 48\%. A mass loss has been also observed, which in both cases compared to original material was about $8 \%$. According to manufacturer data at intensity of $600 \mathrm{~W} / \mathrm{m}^{2}$ in a wavelength range of $300-800 \mathrm{~nm}$ ageing for 100 hours corresponds to about 1.5 month in normal Middle Europe conditions, while in case of 200 hours it is about 2.5 months. Thanks to it, it can be concluded that the use of clothes in a result of exposure to sun radiation causes loss of their protective properties. The studied fabrics besides the reduction of strength became also mores stiff and changed the colour comparing to the raw fabric. They became darker. In this case, all samples obtained positive results for the required strength according to PN-EN 469:2008 standard. 


\subsection{Fabric after abrasion cycles}

Below the results of tensile strength studies of fabrics after abrasion in a range of 20000 and 40000 abrasion cycles are presented. Due to area of abrasion the studies were carried out on the samples with dimensions of $3.5 \times 20 \mathrm{~cm}$.

- Sample after 20000 abrasion cycles

Table 5. Results after 20000 abrasion cycles, specimen's dimensions 3.5 x $20 \mathrm{~cm}$.

\begin{tabular}{|c|c|c|c|c|}
\hline & Sample 1 & Sample 2 & Sample 3 & Average value \\
\hline Thickness [mm] & 0,40 & 0,40 & 0,39 & 0,40 \\
\hline Weight [g/cm $\mathbf{2}]$ & 0,0209 & 0,0196 & 0,0199 & 0,0201 \\
\hline Destructive force value FH [N] & 463,22 & 382,95 & 432,78 & 426,32 \\
\hline
\end{tabular}

- $\quad$ Specimen after 40000 abrasion cycles

Table 6. Results after 40000 abrasion cycles, specimen's dimensions 3.5 x $20 \mathrm{~cm}$.

\begin{tabular}{|c|c|c|c|c|}
\hline & Sample 1 & Sample 2 & Sample 3 & Average value \\
\hline Thickness [mm] & 0,38 & 0,38 & 0,38 & 0,38 \\
\hline Weight $\left[\mathbf{g} / \mathbf{c m}^{\mathbf{2}}\right]$ & 0,0195 & 0,0189 & 0,0185 & 0,0190 \\
\hline Destructive force value FH [N] & 191,51 & 201,09 & 147,96 & 180,19 \\
\hline
\end{tabular}

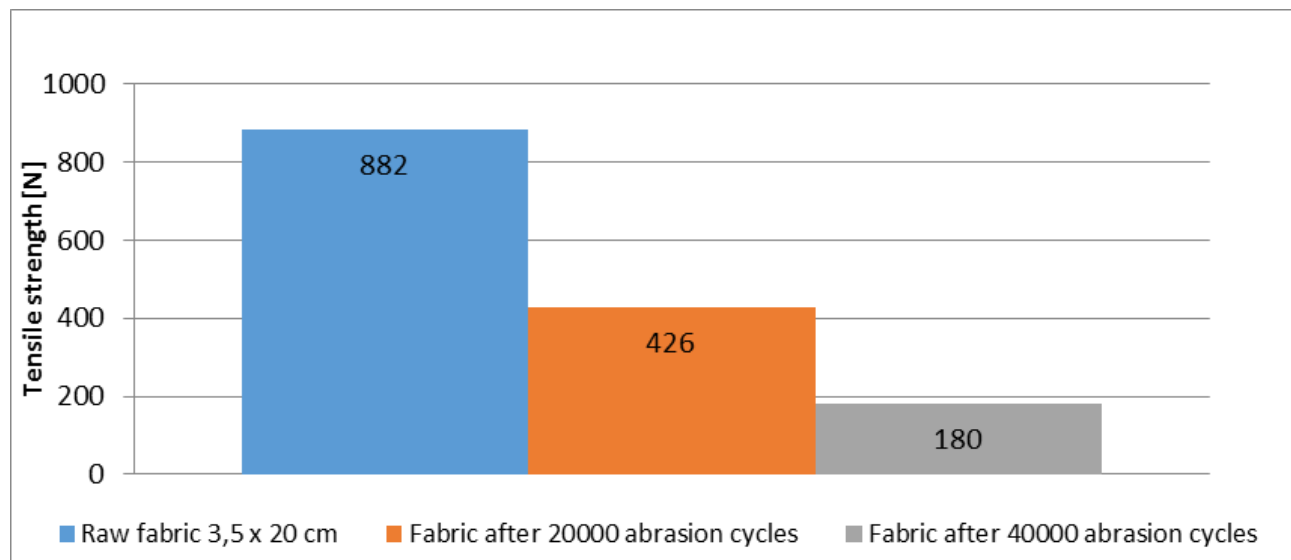

Fig. 2. Figure of average values of tensile strength for fabric after abrasion cycles References: own studies

For the fabric exposed to abrasion test change of colour in area where material was rubbed by abrasive material was shown. As a result of observation and additional measurements it has been found that besides a visible fabric discolouring, its mass and thickness decreased at the area of friction. For 20000 cycles of friction a strength drop comparing to raw fabric was about $52 \%$, while for 40000 friction cycles it was $80 \%$. Tensile strength value already after 2000 friction cycles does not comply with minimum requirements for outer layer included in PN-EN 469:2008 standard. After 20000 friction cycles the observed mass loss was about $7 \%$, while thickness decreased by $2 \%$. In case of 40000 friction cycles, mass decreased by $12 \%$, while thickness decreased by $7 \%$. 


\section{Conclusion}

Special clothing is a protective clothing used by the officers from the State Fire Brigade. During many years changing manufacturing technology ensured use of better and better materials, protecting rescuer against thermal radiations and mechanical damages. A purpose of conducted studies was to analyse tensile strength of the selected fabric used for manufacturing of outer layer of protective clothing for firefighters. New (raw) material has a strength value above $1000 \mathrm{~N}$, which in relation to PN EN 469 standard and included requirements means they are met with a large excess. Outer factors applied for the accelerated wear of fabric, it is UV radiation effect and abrasion, simulated process of fabric wear in working conditions. The results of studies have shown their significant impact on the mechanical strength of material. In case of exposure of material to radiation for 100 and 200 hours, a decrease in strength by approx. $34-48 \%$ has been observed. Analysing results of tensile strength tests for material, which was abraded in 20000 and 40000 friction cycles, there has been a reduction of strength level by approx. $52-80 \%$. The studies have demonstrated that clothing with use over time lose their protective properties. It can be concluded that based on the study results, exposure time to radiation in a chamber with xenon lamps equals $200 \mathrm{~h}$, which corresponds to radiation conditions absorbed during about 3 months, is a critical time for the studied material of the outer layer of clothing.

For the abrasive wear tensile strength after 20000 cycles has dropped below acceptable level of $450 \mathrm{~N}$ constituting the lower threshold for tensile strength of material of special firefighter's clothing according to PN-EN 469:2008.

\section{References}

1. PN-EN 469:2008

2. http://archiwum.ciop.pl/25666.html

3. R. Kamocka-Bronisz, M. Blukacz, S. Bronisz, Zeszyty Naukowe SGSP 58:2/2, 119 (2016)

4. R. Kamocka-Bronisz, S. Bronisz, Zeszyty Naukowe SGSP 66:2/2, 27 (2018)

5. R. Kamocka-Bronisz, S. Bronisz, Zeszyty Naukowe SGSP 62:2/2, 7 (2017)

6. PN-EN ISO 13934-1:2013-07 